\section{Pancreatic endoscopic ultrasound-assisted rendez- vous procedure to facilitate drainage of nondilated pancreatic ducts}

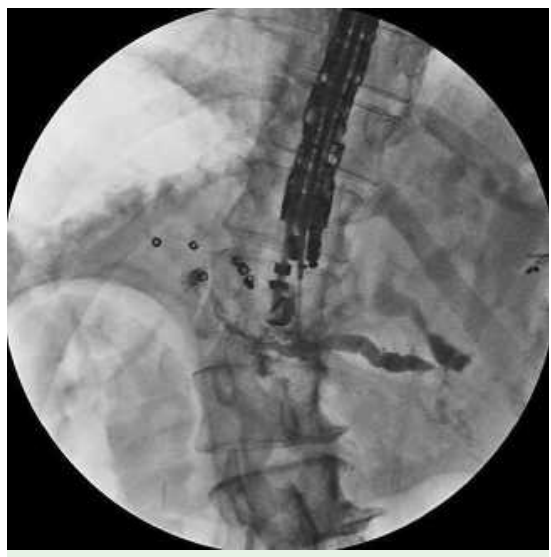

Fig. 1 Fluoroscopic image showing puncture of the main pancreatic duct with a 22-gauge needle (pancreatic duct diameter $2.5 \mathrm{~mm}$ ).

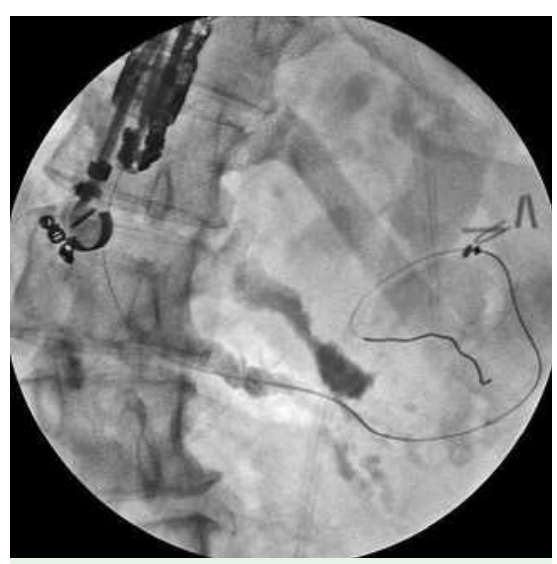

Fig. 2 A 0.018-inch guide wire was advanced across the pancreatic duct into the duodenum.

The use of therapeutic transmural endoscopic ultrasound-assisted rendezvous procedures has been reported previously in patients with obstructive chronic pancreatitis [1 -5]. However, there have been no reports describing the use of this technique in patients with normal pancreatic duct dimensions.

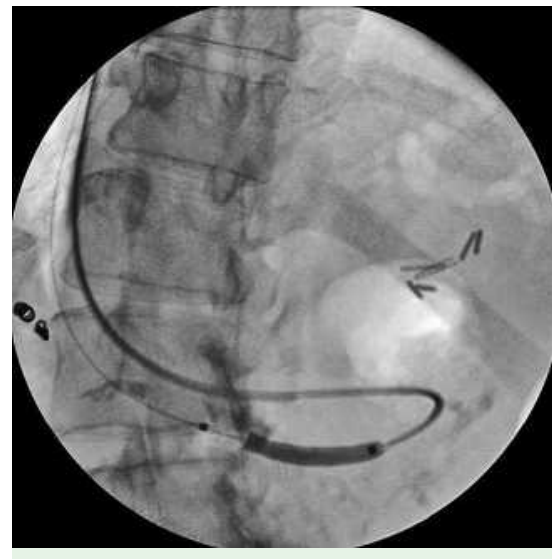

Fig. 3 Balloon dilation of the pancreatic duct at the pancreatic head was performed under fluoroscopic guidance.

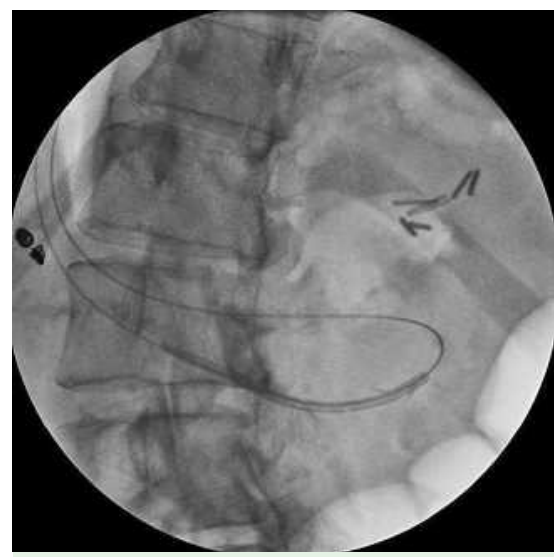

Fig. 4 Transpapillary pancreatic duct stent insertion was then performed under fluoroscopic guidance.

We present two patients, a 42-year-old woman with a history of recurrent acute pancreatitis and a tight, inaccessible pancreatic duct stricture seen at endoscopic retrograde cholangiopancreatography which was associated with an upstream fluid collection (patient A), and a 37year-old woman with postsurgical Whip- ple anatomy who presented with persistent abdominal pain, in whom endoscopic retrograde cholangiopancreatography confirmed the presence of a widely patent hepaticojejunostomy but failed to identify the pancreatic duct orifice, despite the administration of secretin (patient B).

A transgastric approach using a 22-gauge endoscopic ultrasound needle allowed access to the pancreatic duct upstream from the stricture ( Fig. 1). A 0.018inch guide wire was advanced across the pancreatic duct stricture and was coiled in the duodenum under endoscopic ultrasound and fluoroscopic guidance (ष Fig. 2). After withdrawal of the echo endoscope, a gastroscope was advanced in patient $\mathrm{A}$ and a colonoscope in patient B. A biopsy cable within an Oasis system sheath (Cook Medical, Ireland) was used to grasp and stabilize the leading end of the guide wire. By withdrawing the endoscope, both ends of the guide wire were identified exiting from the patient's mouth. A dilating balloon was advanced over the guide wire, within the pancreatic head, under fluoroscopic guidance but without endoscopic assistance. Balloon dilation was performed, followed by placement of a pancreatic duct stent using the same technique ( $\bullet$ Fig. 3, 4). In this report we have described two patients with pancreatic duct strictures that were inaccessible using traditional techniques, but which were managed using a combined endoscopic, endosonographic, and fluoroscopic pancreatic rendezvous technique. The unique technical aspects of these procedures included the achievement of endoscopic ultrasound access to diminutive pancreatic ducts, and the use of a biopsy cable within a catheter to "snag" the slippery guide wire, followed by balloon dilation and over-the-wire stent placement with limited endoscopic guidance.

Endoscopy_UCTN_Code_TTT_1AR_2AI Endoscopy_UCTN_Code_TTT_1AS_2AD 


\section{G. I. Papachristou, F. C. Gleeson,} B. T. Petersen, M. J. Levy

Division of Gastroenterology and Hepatology, Mayo Clinic Foundation, Rochester, Minnesota, USA

\section{References}

1 Dumonceau JM, Cremer M, Baize M, Deviere J. The transduodenal rendezvous: a new approach to deeply cannulate the main pancreatic duct. Gastrointest Endosc 1999; 50: 274-276

2 Bataille L, Deprez P. A new application for therapeutic EUS: main pancreatic duct drainage with a "pancreatic rendezvous technique". Gastrointest Endosc 2002; 55: $740-743$
3 Mallery S, MatlockJ, Freeman ML. EUS-guided rendezvous drainage of obstructed biliary and pancreatic ducts: report of 6 cases. Gastrointest Endosc 2004; 59: 100-107

4 Kahaleh M, Hernandez AJ, Tokar J et al. EUSguided pancreaticogastrostomy: analysis of its efficacy to drain inaccessible pancreatic ducts. Gastrointest Endosc 2007; 65: 224 230

5 Tessier G, Bories E, Arvanitakis $M$ et al. EUSguided pancreatogastrostomy and pancreatobulbostomy for the treatment of pain in patients with pancreatic ductal dilatation inaccessible for transpapillary endoscopic therapy. Gastrointest Endosc 2007; 65: $233-241$
Bibliography

DOI 10.1055/s-2007-966805

Endoscopy 2007; 39: E324-E325

(C) Georg Thieme Verlag KG Stuttgart · New York . ISSN 0013-726X

\section{Corresponding author}

\section{J. Levy, MD}

Division of Gastroenterology and Hepatology Mayo Clinic College of Medicine 200 First Street SW

Charlton 8

Rochester

Minnesota 55905

USA

Fax: 1-507-266-3939

levy.michael@mayo.edu 